\title{
CLIMATE CHANGE RISK PERCEPTION AND POLICY PREFERENCES: THE ROLE OF AFFECT, IMAGERY, AND VALUES
}

\author{
ANTHONY LEISEROWITZ \\ Decision Research, 1201 Oak Street, Suite 200, Eugene, OR 97401 \\ E-mail: ecotone@uoregon.edu
}

\begin{abstract}
A national, representative survey of the U.S. public found that Americans have moderate climate change risk perceptions, strongly support a variety of national and international policies to mitigate climate change, and strongly oppose several carbon tax proposals. Drawing on the theoretical distinction between analytic and experiential decision-making, this study found that American risk perceptions and policy support are strongly influenced by experiential factors, including affect, imagery, and values, and demonstrates that public responses to climate change are influenced by both psychological and socio-cultural factors.
\end{abstract}

\section{Introduction}

Public risk perceptions are critical components of the socio-political context within which policy makers operate. Public risk perceptions can fundamentally compel or constrain political, economic and social action to address particular risks. For example, public support or opposition to climate policies (e.g., treaties, regulations, taxes, subsidies, etc.) will be greatly influenced by public perceptions of the risks and dangers of global climate change. ${ }^{1}$

In this context, American public risk perceptions of climate change are critical for at least two reasons. First, the United States, with only 5\% of the world's population (U.S. Census Bureau, 2005), is currently the world's largest emitter of carbon dioxide, alone accounting for nearly 25\% of global emissions (Marland et al., 2003). Per capita, Americans emit 5.40 metric tons of carbon each year. By comparison, the average Japanese emits 2.55 tons per year, while the average Chinese emits only 0.60 and the average Indian only 0.29 tons per year (ibid.). Second, successive U.S. presidents and congressional leaders have been at odds with much of the world community regarding the reality, seriousness and need for vigorous action on climate change. In 1997, just prior to the Kyoto climate change conference, the U.S. Senate passed a nonbinding resolution (95-0) co-sponsored by Robert Byrd (D) of West Virginia and Chuck Hagel (R) of Nebraska, which urged the Clinton administration to reject any agreement that did not include emission limits for developing as well as industrialized countries, arguing that to do so would put the U.S. at a competitive economic disadvantage (Senate Resolution, 98, 1997). Further, in 2001 President George W. Bush renounced a campaign pledge to regulate carbon dioxide as a pollutant, withdrew the United States from the Kyoto Protocol 
negotiations, and proposed national energy legislation to increase drilling for oil and natural gas, mining for coal, and build over a thousand new fossil-fuel burning power plants (Pianin and Goldstein, 2001; Revkin, 2001; United States, 2001). Clearly, the American public will play a critical role, both in terms of their direct consumption of fossil fuels and resulting greenhouse gas emissions, and through their support for political leaders or government policies to mitigate or adapt to global climate change.

Since the year 2000, numerous public opinion polls demonstrate that large majorities of Americans are aware of global warming (92\%), believe that global warming is real and already underway $(74 \%)$, believe that there is a scientific consensus on the reality of climate change (61\%), and already view climate change as a somewhat to very serious problem (76\%) (Leiserowitz, 2003; PIPA, 2005). At the same time, however, Americans continue to regard both the environment and climate change as relatively low national priorities. For example, in a 2000 Gallup poll, the environment ranked 16th on Americans' list of most important problems facing the country. Further, global warming ranked 12th out of 13 environmental issues, just below urban sprawl (Dunlap and Saad, 2001). Thus Americans paradoxically seem concerned about global warming, yet view it as less important than nearly all other national or environmental issues. What explains this paradox? Additionally, why do some Americans see climate change as an urgent, immediate danger, while others view it as a gradual, incremental problem, or not a problem at all?

While useful, public opinion polls have limited utility for explaining public risk perceptions of global climate change. Most polls use only relatively simple, holistic measures of concern (e.g., "how serious of a threat is global warming"), which provide little insight into the determinants and components of public risk perception. For example, a critical finding of recent research on risk perception is that public perceptions are influenced not only by scientific and technical descriptions of danger, but also by a variety of psychological and social factors, including personal experience, affect and emotion, imagery, trust, values and worldviews - dimensions of risk perception that are rarely examined by opinion polls (Slovic, 2000).

\subsection{EXPERIENTIAL VS. ANALYTIC PROCESSING OF RISK}

"Virtually all current theories of choice under risk or uncertainty are cognitive and consequentialist" (Loewenstein et al., 2001, p. 267). These rational choice models typically assume that people analytically assess the desirability and likelihood of possible outcomes to arrive at a calculated decision. This assumption also underlies the expected-utility model that informs much of economic and psychological theory. Past research has thus attempted to model how people make rational, analytical choices. Affect (a person's good or bad, positive or negative feelings about specific objects, ideas or images) and emotions (e.g., anger, fear) are typically ignored in these models or viewed as mere epiphenomena of the decision making 
process. Thus, most theorists assume that decision making about risk is essentially a cognitive activity.

"affect. . has rarely been recognized as an important component in human judgment and decision making. Perhaps befitting its rationalistic origins, the main focus of descriptive decision research has been cognitive, rather than affective" (Slovic et al., 2002, p. 397).

Likewise, recent academic research on the American public's perception of global climate change has described and analyzed the public's accurate and inaccurate mental models of climate change causation (Bostrom et al., 1994; Kempton et al., 1995; Read et al., 1994). For example, Kempton et al. found that Americans have assimilated information on global climate change into pre-existing mental models of stratospheric ozone depletion and the ozone hole. This has led to important misconceptions and confusions between the two environmental issues. Many people mistakenly believe that stratospheric ozone depletion is a cause of climate change. They also believe that ozone depletion is caused by aerosol spray cans. This leads to the logical, but mistaken inference that banning aerosol spray cans is an effective solution to climate change. Thus, mental model researchers have discovered some critical misconceptions held by the American public.

Mental model approaches, however, are still primarily cognitive. They focus on the role of scientific information and knowledge in the formation of the American public's environmental beliefs and misconceptions. Environmental scientists, decision makers and risk communicators are increasingly aware, however, that simply providing more detailed and accurate information, while important, is not sufficient to generate appropriate public concern for some risks or to allay public fears about others. Mental model researchers have analyzed how people make inferences about the causes of climate change, but not how risk perception and behavior are guided by emotion and affect.

Critiquing the cognitive paradigm underlying most risk perception and mental models research, Zajonc (1980) argued that affective reactions to stimuli are evoked automatically and subsequently guide rational information processing and judgment. Affect and feelings are not mere epiphenomena, but often arise prior to cognition and play a crucial role in subsequent rational thought. A large and growing literature has since emerged in several fields providing convergent lines of evidence for the critical role of affect in risk perception and decision making (Alhakami and Slovic, 1994; Damasio, 1994, 1999; Epstein, 1994; Lowenstein, 1996; Lowenstein et al., 2001; Peters and Slovic, 1996; Slovic et al., 1991, 1998). This literature is part of broader empirical and theoretical developments distinguishing "two parallel, interacting modes of information processing: a rational system and an emotionally driven experiential system" (Epstein, 1994, p. 709). The rational processing system is analytic, logical, and deliberative and encodes reality in abstract symbols, words and numbers. In contrast, the experiential system is holistic, affective and intuitive 
and encodes reality in concrete images, metaphors and narratives linked in associative networks. Summarizing the convergent findings of numerous research studies, Epstein states that "experientially derived knowledge is often more compelling and more likely to influence behavior than is abstract knowledge" (Epstein, 1994, p. 711). Likewise, Nisbett and Ross (1980) argue that vivid, concrete information has a greater influence on perceptions and inferences than 'pallid' (e.g., abstract and technical) information. Among other findings, this research has identified an 'affect heuristic' - an orienting mechanism that allows people to navigate quickly and efficiently through a complex, uncertain and sometimes dangerous world, by drawing on positive and negative feelings associated with particular risks (Alhakami and Slovic, 1994; Finucane et al., 2000). This research trajectory has also developed affective image analysis - a structured form of word association and content analysis - as an invaluable method to investigate the relationship between affect, imagery and perceived risk (e.g., Benthin et al., 1995; Jenkins-Smith, 2001; Leiserowitz, 2005; Satterfield, 2001; Slovic et al., 1991).

\subsection{AFFECTIVE IMAGERY AND ANALYSIS}

"Of all the imps that inhabit the nervous system, that little black box in psychological theorizing - the one we call meaning - is held by common consent to be the most elusive. Yet again by common consent of social scientists, this variable is one of the most important determinants of human behavior" (Osgood et al., 1957).

"associations are simply a remarkably easy and efficient way of determining the contents of human minds without having those contents expressed in the full discursive structure of language" (Szalay and Deese, 1978, p. 9).

Again, affect refers to a person's good or bad, positive or negative feelings about specific objects, ideas or images. Imagery refers to all forms of mental representation or cognitive content. Images include both perceptual representations (pictures, sounds, smells) and symbolic representations (words, numbers, symbols) (Damasio, 1999, pp. 317-321). In this sense, 'image' refers to more than just visually-based mental representations. Affective images thus "include sights, sounds, smells, ideas, and words, to which positive and negative affect or feeling states have become attached through learning and experience" (Slovic et al., 1998, p. 3). Finally, affective image analysis uses a structured and systematic form of word association (described below) to identify the positive and negative connotations and symbolic meanings associated with particular hazards. Free associations minimize the researcher bias potentially imposed in closed questionnaires; they are unfiltered, relatively contextfree, and spontaneous, thus providing a unique means to access and assess subjective meaning. ${ }^{2}$ This simple, yet powerful measure allows researchers to 'map' the 
distribution of different, and often conflicting, meanings of risk across individuals, groups and populations. The study of affective images in risk perception attempts to identify, describe, and explain those images that carry a strongly positive or negative emotional 'charge,' and guide risk decision-making. For example, an early study found that many of the images the American public associated with the stimulus "nuclear waste repository" (images such as death, cancer, and the mushroom cloud) evoked strong feelings of dread and judgments that a proposed nuclear waste repository was an extremely dangerous risk (Slovic et al., 1991). More broadly, these images also influenced risk perceptions of nuclear energy and were strongly associated with intended voting behavior (Slovic et al., 1991) and support (or the lack thereof) for construction of new nuclear power plants (Peters and Slovic, 1996).

\subsection{VALUES AND RISK PERCEPTION}

Cultural theorists argue that social values and worldviews also play an important role in risk perception and behavior. Originating in the work of anthropologist Mary Douglas (Douglas, 1966, 1970; Douglas et al., 1998; Douglas and Wildavsky, 1982), cultural theory focuses on how different individuals and groups interpret the world in different, yet patterned ways. Worldviews are defined by Dake $(1991,1992)$ and Dake and Wildavsky $(1990,1991)$ as general social, cultural and political attitudes toward the world and "orienting dispositions" that guide individual responses in complex situations. Worldviews are mediated by social relations; an individual is either more group-oriented or individual-oriented. Likewise, an individual believes that many socially stratified rules are needed to control behavior, or that few rules are necessary. "In a $2 \times 2$ matrix of social relations by level of prescription, four basic worldviews emerge: hierarchical, fatalistic, individualistic, and egalitarian" (Peters and Slovic, 1996, p. 1430). These are, however, only ideal types: "This typology is a heuristic device; few individuals should be expected to hold to these extreme positions consistently" (Jaeger et al., 1998, p. 191).

Cultural theorists argue that hierarchists, individualists, egalitarians and fatalists each identify and define different risks; those that threaten their own preferred way of life. Each worldview thus represents a different 'rationality;' a set of presuppositions about the ideal nature of society which leads each group to perceive different risks and prefer different policy responses. Prototypical hierarchists most fear social deviance, which threatens the structure of status quo. They call for the active management of risk by 'experts,' in whom they place great trust. Prototypical individualists most fear restrictions on their autonomy, such as government regulation. They promote market-based strategies that maintain their autonomy and provide opportunities for personal gain, believing that the 'invisible hand' of self-interested actors seeking to maximize their own personal gain - leads to optimal social results. Both hierarchists and individualists tend to embrace technology, which is viewed instrumentally as providing either more social control (if 
sanctioned by the 'experts') or more individual efficacy, respectively. Prototypical egalitarians, however, are most concerned about injustice in the distribution of risk costs and benefits, tolerate or celebrate social deviance and diversity, and view technology with suspicion. They often promote participatory, democratic, and consensus-based decision-making that includes all affected parties as equals (Dake and Wildavsky, 1990; Dake, 1991, 1992; Milton, 1996; Pendergraft, 1998; Slovic and Peters, 1998; O'Riordan and Jordan, 1999; Steg and Sievers, 2000). Cultural theory, however, is "sometimes criticized because it lacks empirical testing via organized case studies and recognized social science techniques" (O'Riordan and Jordan, 1999, p. 88). This research study operationalized cultural theory as an independent set of variables to test the theorized relationship between worldview values and risk perceptions and policy preferences.

\section{Hypotheses}

Drawing on these recent theoretical developments in the fields of decision making and risk perception, this research was designed to test the following hypotheses:

1. Affective images of global warming influence (a) global warming risk perceptions and (b) individual support for climate policies.

2. Cultural values have a separate, but related influence on (a) global warming risk perceptions and (b) individual support for climate policies.

\section{Methods}

\subsection{PROCEDURE AND RESPONDENTS}

A national study of American global climate change risk perceptions, affective images, values, and policy preferences was conducted from November, 2002 to February, 2003. The study was implemented with a 16-page mail-out, mail-back survey of a representative sample of the American public, using the Dillman (2000) tailored design method. A total of 673 completed surveys were returned for an overall CASRO response rate of $55.4 \%$ and a refusal rate of $11.2 \%$. Compared to population distributions from the 2000 U.S. Census, the sample over-represented males (65\%) and persons 55 and older (47\%). The results were weighted by sex and age to bring them in line with actual population proportions.

\subsection{MEASURES}

\subsubsection{Risk Perception}

Several measures of public risk perceptions were implemented, including holistic concern; assessments of the severity of current and future impacts of global climate 
change on human health (mortality and morbidity); likelihood measures of local and global impacts of climate change on standards of living, water shortages and rates of serious disease; the seriousness of the threat to non-human nature; the seriousness of the current impacts of climate change around the world, and the scale of concern. For analysis, a 'Risk Perception Index' was constructed by combining nine of these variables: holistic concern; likelihood measures of worldwide and local impacts of global warming on standards of living, water shortages and disease; the seriousness of global warming for non-human nature; and the seriousness of the current impacts of global warming around the world $(\alpha=0.94)$ (see appendix for full questions).

\subsubsection{Holistic Affect and Affective Imagery}

Holistic affective evaluations of global warming were gathered using separate, unipolar measures of negative and positive affect. Respondents were first asked, "Do you have any negative feelings about global warming?" If so, they were then asked to rate the strength of their negative feelings on a 5-point Likert scale ranging from slightly negative $(-1)$ to very negative $(-5)$. They were then asked, "Do you have any positive feelings about global warming?" If so, they then rated the strength of their positive feelings on a 5-point Likert scale ranging from slightly positive $(+1)$ to very positive $(+5)$.

Affective images are comprised of both cognitive content (images) and affective evaluation (affect). Images were gathered using the method of continued word associations (Szalay and Deese, 1978; Slovic et al., 1991; Peters and Slovic, 1996). Respondents were asked, "What is the first thought or image that comes to your mind when you think of global warming?" In response, survey participants provided either single word associations (e.g., "disaster") or short narrative statements. Each self-reported association was then evaluated by the respondent on a bi-polar affect scale ranging from -5 (very negative) to +5 (very positive). For example, if a respondent associated global warming with "melting glaciers," they were then asked "How strong are your negative or positive feelings about melting glaciers?" A rich dataset of over 700 respondent images and affective evaluations were generated by this technique. An inductive content analysis was then performed with two independent coders to reduce the responses into 24 categories, in the tradition of grounded theory, in which respondents' predominant replies reveal the main themes. The mean affect was then calculated for each category.

\subsubsection{Values}

Values derived from Cultural Theory (egalitarianism, fatalism, hierarchism and individualism) were operationalized using a set of 25 questions selected in part from scales used by Dake (1991, 1992), Peters and Slovic (1996) and Rippl (2002). For analysis, two value indices were constructed: an 'Egalitarianism Index' $(\alpha=0.77)$ and a 'Fatalism Index' ( $\alpha=0.71)$ (see appendix for full questions). Indexes were attempted for both Hierarchism and Individualism measures (6 statements each), but each failed to achieve a satisfactory Cronbach alpha ( 0.50 for Hierarchism and 
0.52 for Individualism), therefore each Hierarchism and Individualism variable was individually correlated with the dependent variables in an attempt to identify theoretically relevant predictor variables.

\subsubsection{Climate Policy Preferences}

Respondents were asked to indicate their level of support or opposition to ten different climate change policy proposals, at both the national and international levels. Measures included support for U.S. reduction of greenhouse gases, the Kyoto Protocol, U.S. action with or without the participation of other developed or developing countries, an international market in emissions trading, the regulation of carbon dioxide as a pollutant, higher fuel economy standards, a sixty cent per gallon gasoline tax, a three percent business energy tax, a five percent 'gas guzzler' tax, and a shifting of government subsidies from the fossil fuel industry to the renewable energy industry (see appendix for full questions). For analysis, a 'Policy Preferences Index' $(\alpha=0.84)$ and a 'Tax Policy Preferences Index' ( $\alpha=0.78)$ were constructed (see appendix).

\subsubsection{Sociodemographics}

Finally, sociodemographic measures included sex, age, income, educational attainment, race or ethnicity, main source of news, political party identification (Republican, Independent, Democrat), political ideology (conservative, moderate, liberal) and voter registration. Detailed descriptions of all variables are available upon request.

\section{Results}

\subsection{AMERICAN RISK PERCEPTIONS}

Americans as a whole perceived global climate change as a moderate risk (Figure 1). On average, Americans were somewhat concerned about global warming, believed that impacts on worldwide standards of living, water shortages and rates of serious disease are somewhat likely and that the impacts will be more pronounced on nonhuman nature. Importantly, however, they were less concerned about local impacts, rating these as somewhat unlikely. The moderate level of public concern about climate change thus appears to be driven primarily by the perception of danger to geographically and temporally distant people, places and non-human nature.

This conclusion is supported by the results of a separate question that asked respondents to indicate which scale of climate change impacts was of greatest concern to them (Table I). The question asked, "Which of the following are you most concerned about? The impacts of global warming on... (1) you and your family; (2) your local community; (3) the U.S. as a whole; (4) people all over the world; (5) non-human nature; or, (6) not at all concerned." 


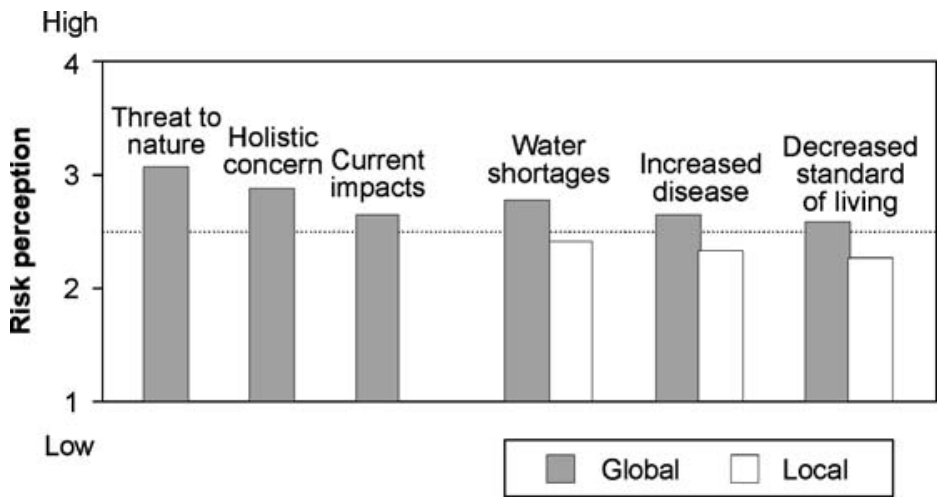

Figure 1. American risk perceptions of global warming. Scales range from 1 (low) to 4 (high). Response categories include seriousness of threat to nature and current impacts around the world (not at all to very serious); level of concern about global warming (not at all to very concerned); and the likelihood of specific impacts locally and worldwide (very unlikely to very likely). $n=590$.

TABLE I

Most concerned about impacts on?

\begin{tabular}{lrc}
\hline & Percent & Cumulative \% \\
\hline You and your family & 12 & 12 \\
Your local community & 1 & 13 \\
The U.S. as a whole & 9 & 22 \\
People all over the world & 50 & 72 \\
Non-human nature & 18 & 90 \\
Not at all concerned & 10 & 100 \\
Total & 100 & \\
\hline
\end{tabular}

$n=551$.

A clear majority of respondents $(68 \%)$ were most concerned about the impacts on people around the world and non-human nature. Only $13 \%$ were most concerned about the impacts on themselves, their family or their local community. This may help explain why global climate change remains a relatively low priority in issue ranking surveys (e.g., Dunlap and Saad, 2001). Higher-ranking national issues (e.g., the economy, education, health care) and environmental issues (clean air, clean water, urban sprawl) are all issues that are more easily understood as having direct local relevance. 'Global' climate change, however, is not yet perceived as a significant local concern among the American public. Former Speaker of the U.S. House of Representatives Tip O'Neill once famously stated "all politics is local." To the extent that this is true, climate change is unlikely to become a high-priority national issue until Americans consider themselves personally at risk. 

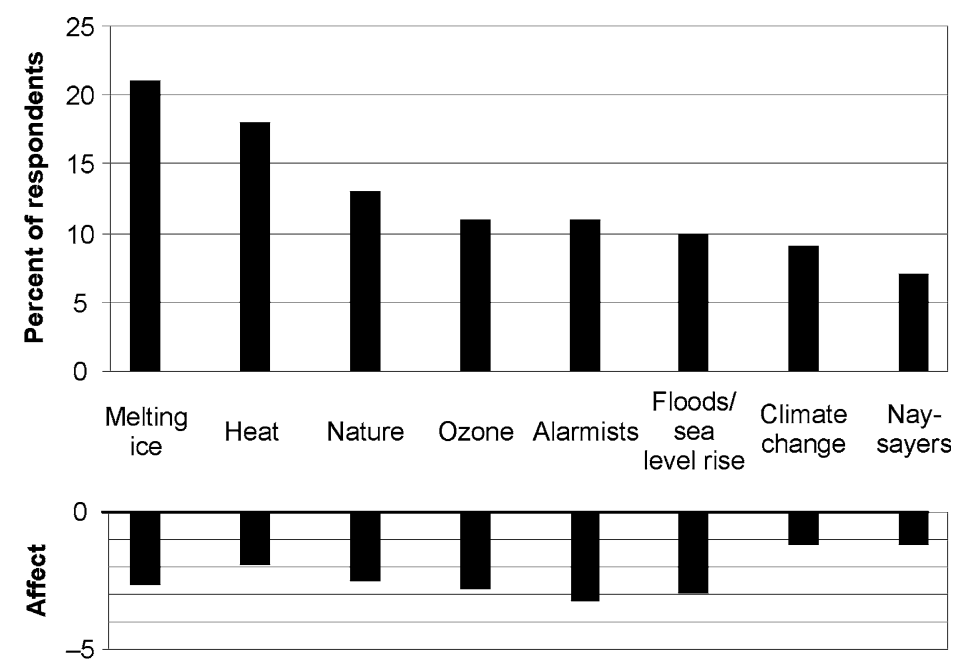

Figure 2. American images of global warming. Affect was rated on a 10-point scale where $+5=$ very positive and $-5=$ very negative. Affect scores are the mean affect for each category of images. $n=558$.

\subsection{AMERICAN IMAGES OF GLOBAL WARMING}

This analysis identified a total of 24 distinct thematic categories of affective images associated with global warming. The top eight categories, however, represent $97 \%$ of all respondents (Figure 2). Associations to melting glaciers and polar ice were the single largest category of responses, indicating that this current and projected impact of climate change was the most salient image among the American public (e.g., "melting polar ice caps" "Antarctica melting"). This was followed by generic associations to heat and rising temperatures (e.g., "temperatures increasing"), impacts on non-human nature (e.g., "upset ecological balance"), ozone depletion (e.g., "a hole in the ozone layer"), alarmist images of disaster (e.g., "world devastation" "the end of the world as we know it"), sea level rise and the flooding of rivers and coastal areas (e.g., "rising ocean levels" "flooding of Manhattan"), references to climate change ("a change in climate"), and finally associations indicating skepticism or cynicism about the reality of climate change (naysayers). A more detailed content analysis of naysayers' affective images revealed five distinct reasons why they doubted the reality of global climate change:

(1) Belief that global warming is natural ("Normal earth cycles" "It is just the natural course of events" "A natural phenomenon that has been going on for years").

(2) Hype ("It is not as bad as the media portrays" "The 'problem' is overblown" "Environmentalist hysteria"). 
(3) Doubting the science ("There is no proof it exists" "Around 10 years or so ago it was global cooling" "Junk science").

(4) Flat denials of the problem ("A false theory" "There is no global warming").

(5) Conspiracy theories ("Hoax" "Environmentalist propaganda" "Scientists making up some statistics for their job security").

Mean affect scores (Figure 2) indicate that the term "global warming" evoked negative connotations for almost all respondents. Alarmist images of disaster produced the strongest negative affect, while naysayers displayed very low negative affect.

Thus, two of the four most dominant images (melting ice and non-human nature), provided by $34 \%$ of all respondents, referred to impacts on places or natural ecosystems distant from the everyday experience of most Americans. Most of the references to "heat" were relatively generic in nature and likely indicated associations with the word "warming" in "global warming." Finally, $11 \%$ of Americans provided associations to the separate environmental issue of stratospheric ozone depletion, indicating that a substantial proportion of Americans continue to confuse and conflate these two issues. Thus, $62 \%$ of Americans provided associations to impacts geographically and psychologically distant, generic increases in temperature, or to a different environmental problem. Critically, this study found that most Americans lacked vivid, concrete, and personally-relevant affective images of climate change, which helps explain why climate change remains a relatively low priority national or environmental issue.

\subsection{AMERICAN POLICY PREFERENCES}

Despite these moderate risk perceptions, however, does the American public support public policies to mitigate climate change? This study measured American public support for a variety of policy proposals to mitigate global warming at the national and international levels (Figure 3). It found that of those Americans who had heard of global warming (92\%):

- $90 \%$ thought the United States should reduce its greenhouse gas emissions.

- 88\% supported the Kyoto Protocol and 76\% wanted the United States to reduce greenhouse gas emissions regardless of what other countries do.

- 79\% supported an increase in vehicle fuel economy standards (CAFE).

- 77\% supported government regulation of carbon dioxide as a pollutant and a shift in subsidies from the fossil fuel industry to the renewable energy industry $(71 \%)$.

- While a majority favored a tax on "gas guzzlers" (54\%), large majorities opposed a gasoline tax $(78 \%)$ or a business energy tax $(60 \%)$ to reduce greenhouse gas emissions. 


\section{Public Support for Climate Policies}

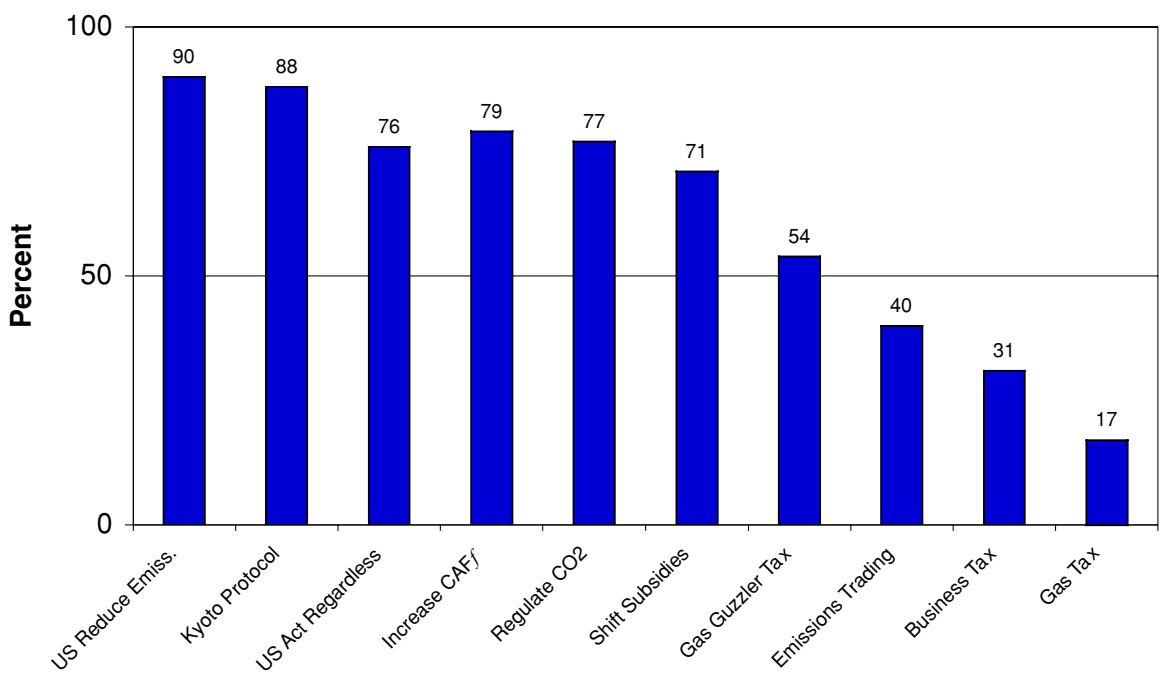

Figure 3. American public support for climate change policies. ${ }^{3} n=568$ to 575 .

- Americans divided evenly (40\%) regarding a market-based emissions trading system, while $18 \%$ were uncertain.

- Democrats and liberals expressed stronger support for climate change policies than Republicans and conservatives.

- Independents and moderates showed levels of support more similar to Democrats and liberals than to Republicans and conservatives, yet:

- Majorities of Republicans and conservatives supported most climate change policies.

This research thus identified a contradiction in American climate change risk perceptions and policy preferences. On the one hand, Americans expressed moderate levels of concern about the issue, strongly believed that the U.S. should reduce its greenhouse gas emissions, strongly supported national regulation of carbon dioxide as a pollutant, and strongly supported international treaties to reduce emissions, like the Kyoto Protocol. On the other hand, the public strongly opposed an increase in business energy and gasoline taxes - both direct pocketbook issues. A majority of Americans did support a tax on "gas guzzler" vehicles, but they were evenly split regarding an international market in emissions trading. Thus, the public largely supported policy action at the national and international levels, but opposed two tax policies that would directly affect them. 


\subsection{THE ROLES OF AFFECT, IMAGERY AND VALUES IN RISK PERCEPTION AND POLICY PREFERENCES}

Hypothesis 1 predicted that affective images of global warming would influence (a) global warming risk perceptions and (b) individual support for climate policies. Hypothesis 2 predicted that values would have a separate, but related influence on (a) global warming risk perceptions and (b) individual support for climate policies. To test these hypotheses multiple regression models were constructed to examine the separate and combined influence of affect, imagery, values, and sociodemographics (independent variables) on several dependent variables: (1) global warming risk perception (Risk Perception Index); (2) climate change policy preferences (General Policy Preferences Index); and, (3) climate tax policy preferences (Tax Policy Index).

\subsubsection{Models of Global Warming Risk Perception}

Model 1 found that holistic negative affect and image affect were very significant predictors of global warming risk perception and explained $32 \%$ of the variance $\left(F(2,402)=93.95, p<.001, R_{\text {adj. }}^{2}=.32\right)($ Table II $){ }^{5}$ As negative affect increased, risk perception increased. Model 2 found that several cognitive image categories including Naysayers, Alarmists, Politics, Don't Know, and Dry/Desert significantly predicted global warming risk perception and together explained $24 \%$ of the variance $\left(F(5,542)=34.75, p<.001, R_{\text {adj. }}^{2}=.24\right)$. Naysayers, Politics and Don't Know were associated with lower perceived risk. Alarmists and Dry/Desert, however, were associated with higher perceived risk. Together, the results of Models 1 and 2 supported Hypothesis 1(a): affective imagery influences risk perception.

Model 3 found that three value measures were significant predictors of global warming risk perception, including the Egalitarianism Index, an individualism variable and a hierarchism variable. As described above, individualism and hierarchism indexes were attempted, but could not be satisfactorily constructed. Instead, each individualism and hierarchism question was regressed on risk perception to identify potential predictors in line with Cultural Theory. Two measures were identified as bivariate correlates with risk perception and therefore included in the model: the individualism statement, "The government should get out of our way" and the hierarchism statement, "When the risk is very small, it is OK for society to impose that risk on individuals without their consent." Egalitarianism was correlated with increased risk perception, while these individualism and hierarchism variables were correlated with decreased risk perception. The full values regression model significantly predicted global warming risk perception and explained $26 \%$ of the variance $\left(F(3,547)=65.57, p<.001, R_{a d j}^{2}=.26\right)$. Thus, this model supported Hypothesis 2(a): values influence risk perception.

Model 4 found six sociodemographic variables that were significant predictors of global warming risk perception. Females, minorities, liberals, members of environmental groups and newspaper readers all tended to perceive global warming 
TABLE II

Multiple regressions on global warming risk perception

\begin{tabular}{|c|c|c|c|c|c|}
\hline Independent variables & $\begin{array}{c}\text { Model } 1 \\
\text { Affect }\end{array}$ & $\begin{array}{l}\text { Model } 2 \\
\text { Images }\end{array}$ & $\begin{array}{l}\text { Model } 3 \\
\text { Values }\end{array}$ & $\begin{array}{c}\text { Model } 4 \\
\text { Sociodems }\end{array}$ & $\begin{array}{l}\text { Model } 5 \\
\text { Full }\end{array}$ \\
\hline Holistic negative affect & $0.41^{* * *}$ & & & & $0.32^{* * *}$ \\
\hline Negative image affect & $0.26^{* * *}$ & & & & $0.19^{* * *}$ \\
\hline Naysayers & & $-0.32^{* * *}$ & & & $-0.21^{* * *}$ \\
\hline Alarmists & & $0.14^{* * *}$ & & & 0.06 \\
\hline Politics & & $-0.17^{* * *}$ & & & $-0.09^{*}$ \\
\hline Don't know & & $-0.11^{* *}$ & & & -0.07 \\
\hline Dry/desert & & $0.18^{* * *}$ & & & $0.09^{*}$ \\
\hline Egalitarianism & & & $0.45^{* * *}$ & & $0.11^{*}$ \\
\hline $\begin{array}{l}\text { The government should get out } \\
\text { of our way. (I) }\end{array}$ & & & $-0.11^{* *}$ & & -0.05 \\
\hline $\begin{array}{l}\text { When the risk is very small, it is } \\
\text { OK for society to impose that } \\
\text { risk on individuals without } \\
\text { their consent. }(\mathrm{H})\end{array}$ & & & $-0.15^{* * *}$ & & -0.04 \\
\hline Female & & & & $0.22^{* * *}$ & $0.10^{*}$ \\
\hline White/Caucasian & & & & $-0.15^{* * *}$ & -0.07 \\
\hline Political Ideology & & & & $-0.24^{* * *}$ & 0.00 \\
\hline Registered Voter & & & & $-0.13^{* * *}$ & 0.04 \\
\hline Member of environmental groups & & & & $0.14^{* * *}$ & $0.10^{* *}$ \\
\hline Newspaper & & & & $0.09^{*}$ & 0.04 \\
\hline$F$ & $93.95^{* * *}$ & $34.75^{* * *}$ & $65.57^{* * *}$ & $23.04^{* * *}$ & $22.76^{* * *}$ \\
\hline Adjusted $R^{2}$ & 0.32 & 0.24 & 0.26 & 0.20 & 0.47 \\
\hline$N$ & 403 & 548 & 551 & 540 & 388 \\
\hline
\end{tabular}

Dependent variable: Risk perception index.

Entries are standardized regression coefficients.

*significant at $0.05 ;{ }^{* *}$ significant at $0.01 ;{ }^{* * *}$ significant at 0.001 .

as a greater risk. Whites, males, conservatives and registered voters, however, all tended to perceive global warming as a smaller risk. The full sociodemographic model significantly predicted global warming risk perception and explained 20\% of the variance $\left(F(6,533)=23.04, p<.001, R_{\text {adj. }}^{2}=.20\right)$.

Finally in Model 5 , the four models were combined to determine which variables were the strongest predictors of global warming risk perception, controlling for the others. Holistic affect was the single most powerful predictor $(\beta=0.32, p<$ $.001)$. The image 'Naysayers' was the second-most powerful predictor $(\beta=-0.21$, $p<.001$ ), again demonstrating that naysayers were much less likely to perceive global warming as a risk. The third-largest predictor was Negative Image Affect $(\beta=0.19, p<.001)$. The fourth-largest predictor was Egalitarianism $(\beta=0.11$, 
$p<.05$ ), showing that egalitarians tended to perceive global warming as a greater risk. Thus, the full multiple regression model demonstrated that affect, imagery and values were stronger predictors than the sociodemographic variables. Furthermore, the full model significantly predicted global warming risk perception and explained $47 \%$ of the variance $\left(F(16,371)=22.76, p<.001, R_{\text {adj. }}^{2}=.47\right)$.

\subsubsection{Models of Global Warming Policy Preferences}

A similar analysis was performed on the Policy Preferences Index, comprised of measures of support and opposition to six proposed national and international policies (Table III). Model 1 found that holistic negative affect significantly predicted support for national policies to address global warming, explaining $12 \%$ of the variance $\left(F(1,417)=60.38, p<.001, R_{\text {adj. }}^{2}=.12\right)$. As holistic negative affect increased, so did support for these national policies. Model 2 found that several images also significantly predicted national policy support. Naysayers, Politics, and Don't Know were all more likely to oppose national policies, while Dry/Desert was more likely to support them. The full model was very significant and explained $29 \%$ of the variance $\left(F(4,551)=57.84, p<.001, R_{\text {adj. }}^{2}=.29\right)$. Together, these two model results provided support for Hypothesis 1(b): affective imagery influences support for national climate policies.

Model 3 found that the Egalitarianism Index, one individualism and two hierarchism measures significantly predicted national policy preferences. Egalitarianism correlated with increased support for national policies, while individualism and hierarchism correlated with increased opposition. The full model was very significant, explained $34 \%$ of the variance $\left(F(4,557)=72.40, p<.001, R_{\text {adj. }}^{2}=.34\right)$, and supported Hypothesis 2(b): values influence support for national climate policies.

Model 4 found that five sociodemographic variables significantly predicted national policy support. Liberals, females, and members of environmental groups were more likely to support national policies to address global warming, whereas conservatives, males, radio-listeners and registered voters were more likely to oppose these policies. The full model was very significant and explained $19 \%$ of the variance $\left(F(5,547)=27.61, p<.001, R_{\text {adj. }}^{2}=.19\right)$.

Finally, in Model 5, the four models were combined into a single multiple regression model, which significantly predicted national policy preferences and explained $44 \%$ of the total variance. 'Naysayers' was the single most powerful predictor $(\beta=-0.32, p<.001)$ of support or opposition to national policies on global warming. The second-most powerful predictor was holistic negative affect $(\beta=0.25, p<.001)$, followed by egalitarianism $(\beta=0.23, p<.001)$. Thus, the full multiple regression model demonstrated that affect, imagery and values were better predictors of support for global warming policies than all sociodemographic variables, including political identification and ideology. 
TABLE III

Multiple regressions on policy preferences

\begin{tabular}{|c|c|c|c|c|c|}
\hline Independent variables & $\begin{array}{l}\text { Model } 1 \\
\text { Affect }\end{array}$ & $\begin{array}{c}\text { Model } 2 \\
\text { Images }\end{array}$ & $\begin{array}{c}\text { Model } 3 \\
\text { Values }\end{array}$ & $\begin{array}{c}\text { Model } 4 \\
\text { Sociodems }\end{array}$ & $\begin{array}{l}\text { Model } 5 \\
\text { Full }\end{array}$ \\
\hline Holistic negative affect & $0.36^{* * *}$ & & & & $0.25^{* * *}$ \\
\hline Naysayers & & $-0.43^{* * *}$ & & & $-0.32^{* * *}$ \\
\hline Politics & & $-0.18^{* * *}$ & & & -0.06 \\
\hline Don't know & & $-0.14^{* * *}$ & & & 0.01 \\
\hline Dry/Desert & & $0.11^{* *}$ & & & 0.03 \\
\hline Egalitarianism & & & $0.48^{* * *}$ & & $0.23^{* * *}$ \\
\hline $\begin{array}{l}\text { When the risk is very small, it is } \\
\text { OK for society to impose that } \\
\text { risk on individuals without } \\
\text { their consent. }(\mathrm{H})\end{array}$ & & & $-0.17^{* * *}$ & & $-0.09^{*}$ \\
\hline $\begin{array}{l}\text { The government should get out } \\
\text { of our way. (I) }\end{array}$ & & & $-0.16^{* * *}$ & & -0.04 \\
\hline $\begin{array}{l}\text { Government and industry can be } \\
\text { trusted to make the right } \\
\text { decisions about technological } \\
\text { risks. }(\mathrm{H})\end{array}$ & & & $-0.09^{* *}$ & & -0.03 \\
\hline Political Ideology & & & & $-0.33^{* * *}$ & $-0.13^{* *}$ \\
\hline Female & & & & $0.11^{* *}$ & $-0.09^{*}$ \\
\hline Member of environmental groups & & & & $0.14^{* * *}$ & 0.03 \\
\hline Radio & & & & $-0.09^{*}$ & 0.01 \\
\hline Registered voter & & & & $-0.12^{* *}$ & -0.06 \\
\hline$F$ & $60.38^{* * *}$ & $57.84^{* * *}$ & $60.59^{* * *}$ & $27.61^{* * *}$ & $23.28^{* * *}$ \\
\hline Adjusted $R^{2}$ & 0.12 & 0.29 & 0.35 & 0.19 & 0.44 \\
\hline$N$ & 419 & 556 & 562 & 553 & 398 \\
\hline
\end{tabular}

Dependent variable: Policy preferences index.

Entries are standardized regression coefficients.

${ }^{*}$ significant at $0.05 ;{ }^{* *}$ significant at $0.01 ;{ }^{* * *}$ significant at 0.001 .

\subsubsection{Models of Global Warming Tax Policy Preferences}

Another multiple regression model tested predictors of support for an index of three national tax policies to mitigate climate change (Table IV). Model 1 found that holistic negative affect significantly predicted support for national tax policies, with increased negative affect associated with increased support. The model, however, while highly significant, explained only $5 \%$ of the variance $(F(1,411)=$ $21.07, p<.001, R_{\text {adj. }}^{2}=.05$ ). Model 2 found that five cognitive image categories (Naysayers, Climate Change, Politics, Alarmists, and Don't Know) significantly predicted tax policy support. These images correlated with opposition to higher taxes, with the exception of Alarmists: respondents in this category were more likely to support higher taxes. The full model was highly significant and explained 
TABLE IV

Multiple regressions on tax policy preferences

\begin{tabular}{|c|c|c|c|c|c|}
\hline Independent variables & $\begin{array}{l}\text { Model } 1 \\
\text { Affect }\end{array}$ & $\begin{array}{c}\text { Model } 2 \\
\text { Images }\end{array}$ & $\begin{array}{l}\text { Model } 3 \\
\text { Values }\end{array}$ & $\begin{array}{l}\text { Model } 4 \\
\text { Sociodems }\end{array}$ & $\begin{array}{l}\text { Model } 5 \\
\text { Full }\end{array}$ \\
\hline Holistic negative affect & $0.22^{* * *}$ & & & & $0.15^{* * *}$ \\
\hline Naysayers & & $-0.21^{* * *}$ & & & $-0.11^{*}$ \\
\hline Climate change & & $-0.19^{* * *}$ & & & -0.07 \\
\hline Politics & & $-0.14^{* * *}$ & & & -0.05 \\
\hline Alarmists & & $0.11^{* *}$ & & & 0.05 \\
\hline Don't know & & $-0.11^{* *}$ & & & -0.01 \\
\hline Egalitarianism & & & $0.41^{* * *}$ & & $0.19^{* * *}$ \\
\hline $\begin{array}{l}\text { Families need a strong authority } \\
\text { figure. }(\mathrm{H})\end{array}$ & & & $-0.13^{* * *}$ & & -0.03 \\
\hline Fatalism & & & $-0.18^{* * *}$ & & -0.05 \\
\hline $\begin{array}{l}\text { If a person has the get-up-and-go } \\
\text { to acquire wealth, that person } \\
\text { should have the right to enjoy } \\
\text { it. (I) }\end{array}$ & & & $-0.14^{* * *}$ & & $-0.13^{* *}$ \\
\hline $\begin{array}{l}\text { Organizations need a strict line of } \\
\text { command to be successful. }(\mathrm{H})\end{array}$ & & & $-0.09^{*}$ & & $-0.09^{*}$ \\
\hline Political Ideology & & & & $-0.28^{* * *}$ & $-0.16^{* *}$ \\
\hline Education & & & & $0.19^{* * *}$ & $0.14^{* *}$ \\
\hline Member of environmental groups & & & & $0.17^{* * *}$ & 0.09 \\
\hline White & & & & $-0.14^{* * *}$ & $-0.09^{*}$ \\
\hline Female & & & & $0.10^{* *}$ & -0.03 \\
\hline$F$ & $21.07^{* * *}$ & $16.57^{* * *}$ & $39.75^{* * *}$ & $24.86^{* * *}$ & $10.91^{* * *}$ \\
\hline Adjusted $R^{2}$ & 0.05 & 0.13 & 0.26 & 0.18 & 0.29 \\
\hline$N$ & 413 & 545 & 552 & 540 & 392 \\
\hline
\end{tabular}

Dependent variable: Tax policy preferences index.

Entries are standardized regression coefficients.

${ }^{*}$ significant at $0.05 ;{ }^{* *}$ significant at $0.01 ;{ }^{* * *}$ significant at 0.001 .

$13 \%$ of the variance $\left(F(5,539)=16.57, p<.001, R_{\text {adj. }}^{2}=.13\right)$. The results supported Hypothesis 1(b): affective images influence support for higher taxes to mitigate climate change.

Model 3 found that the Egalitarianism Index, the Fatalism Index, two hierarchism and one individualism measure significantly predicted tax policy support. Egalitarians were more likely to support higher taxes. Fatalists, hierarchists and individualists were more likely to oppose them. The full model was very significant and explained $26 \%$ of the variance $\left(F(5,546)=39.75, p<.001, R_{\text {adj. }}^{2}=.26\right)$. These results supported Hypothesis 2(b): values influence support for tax policies to mitigate climate change. 
Model 4 found that five sociodemographic variables significantly predicted tax policy support. Conservatives, whites, and males were more likely to oppose higher taxes to mitigate climate change, while liberals, females, minorities, individuals with higher educational achievement, and members of environmental groups were more likely to support higher taxes to mitigate climate change. The full model was very significant and explained $18 \%$ of the variance $(F(5,534)=24.86, p<.001$, $R_{\text {adj. }}^{2}=.18$ ).

Model 5 combined the four models, significantly predicted support for higher taxes to mitigate climate change and explained $29 \%$ of the total variance. Egalitarianism was the single most powerful predictor $(\beta=0.19, p<.001)$ of support. The second-most powerful predictor was political ideology $(\beta=-0.16$, $p<.01)$, followed by holistic negative affect $(\beta=0.15, p<.001)$. Naysayers, individualism, hierarchism, education, and whites remained significant, though weaker predictors in the full model. Thus, values and affect were stronger predictors of support for tax policies than the sociodemographic variables, with the exception of political ideology.

\section{Summary and Discussion}

Overall, the American public was found to have moderate risk perceptions of climate change that appear to be driven primarily by the perception of danger to geographically distant people, places and non-human nature. This conclusion is supported by both the results of a scale of concern question, which found that $68 \%$ said they were most concerned about the impacts of global warming on people all over the world and non-human nature, and an affective image analysis, which found that $62 \%$ of Americans associated global warming with geographically and psychologically distant impacts, generic increases in temperature, or the separate problem of ozone depletion.

This study also found strong bipartisan support among the American public for action at the national and international levels to reduce emissions of greenhouse gases. Significantly, large majorities of the public approved of the regulation of carbon dioxide as a pollutant, supported the Kyoto Protocol, and wanted U.S. action regardless of what other countries do - all contrary to the current policies of the Bush administration and the U.S. Congress. On the other hand, a contradiction in American policy attitudes was identified in these results. While Americans demonstrated high awareness and moderate concern for global warming and strongly supported a variety of government actions, they strongly opposed higher fossil fuel-based energy or gasoline prices to achieve this goal - one of the most powerful and direct economic incentives to reduce fossil fuel use and encourage more energy efficiency (e.g., improved vehicle fuel economy, high efficiency appliances and machinery, etc.). ${ }^{4}$ It thus appears that Americans have not fully confronted the contradiction between their strong support for greenhouse gas emission reductions 
and opposition to selected policies that would directly discourage fossil fuel use by consumers. This suggests that, as a whole, the American public is currently in a "wishful thinking" stage of opinion formation (Yankelovich, 1991, 2002), in which they hope the problem can be solved by someone else (government, industry, etc.), without changes in their own priorities, decision making or behavior. Further, as described above, the American public does not yet perceive climate change as a high-priority or urgent threat, which might necessitate changes in consumer behavior.

This research also operationalized four hypothesized predictors of risk perception and policy preferences among the American public, including negative affect, imagery, values and sociodemographics. A series of multiple regression models were constructed to test these predictors. When all four sets of predictors were combined, the analyses found that negative affect, imagery (naysayers) and values (egalitarian) were consistently stronger predictors of risk perception and policy preferences than all sociodemographic variables, including political party identification and ideology (liberal-conservative). Interestingly, however, holistic negative affect was the strongest predictor of global warming risk perception. These results suggest that risk perception is greatly influenced by affective and emotional factors, including connotative meaning, and provides convergent evidence that public risk assessments are strongly influenced by experiential processes, contrary to most rational choice models (Epstein, 1994; Loewenstein et al., 2001; Slovic, 1997).

Policy preferences, however, were most strongly influenced by value commitments. Support for national and international climate policies was strongly associated with pro-egalitarian values, while opposition was associated with antiegalitarian, pro-individualist and pro-hierarchist values. Interestingly, these value commitments were stronger predictors than either political party identification or ideology. In particular, the consistent finding that egalitarianism was a significant predictor of risk perceptions and policy preferences is all the more remarkable because the egalitarianism measures were not related to global warming, the risk under study, in any direct way. These measures asked respondents how much they agreed or disagreed with statements like, "what this world needs is a more equal distribution of wealth" or "firms and institutions should be organized so everybody can influence important decisions." Despite the nondomain-specific nature of these measures, they nonetheless proved to be highly significant predictors, even after controlling for affect, imagery and sociodemographics. These results thus support one of the predictions of Cultural Theory - that egalitarians are more sensitive to and concerned about environmental risks.

All of these results therefore suggest that underlying values and worldviews strongly condition the way many members of the American public currently think about this risk and public policy options to mitigate global climate change. These findings also imply that risk perception and policy preferences go well beyond 
issues of scientific literacy, analytical reasoning and technical knowledge - instead they suggest that risk perception and policy preferences are strongly influenced by sociopolitical factors as well (Finucane et al., 2000; Slovic, 1997). Future analysis will compare these factors with other potential explanatory variables, such as knowledge, trust and general environmental attitudes.

This study thus found that there is both individual and social psychology at work in public risk perceptions and policy preferences regarding global climate change. The individual connotative meanings associated with "global warming" are important - including both the affective valence (positive or negative) and the specific images evoked by the term. Again, American associations to global warming were dominated by relatively abstract images of geographically or psychologically distant impacts on other people, places, and species. Likewise, risks are not perceived, assessed and responded to in a socio-cultural vacuum by atomized, purely utility-maximizing individuals. Global warming and the policies proposed to mitigate or adapt to it occur within a rich and complex sociopolitical context, in which groups of individuals are socio-politically predisposed to select, ignore and interpret risk information in different ways. Risk perceptions are thus socially constructed, with different groups predisposed to attend to, fear and socially amplify some risks, while ignoring, discounting or attenuating others.

Overall, the findings of this study help explain the paradox in American risk perceptions of climate change. While large majorities of Americans believe climate change is real and consider it a serious problem, it remains a low priority relative to other national and environmental issues. In other words, climate change currently lacks a sense of urgency. These results demonstrate that most of the American public considers climate change a moderate risk that is more likely to impact people and places far distant in space and time. This suggests that efforts to describe the potential national, regional and local impacts of climate change and communicate these potential impacts to the public are critical (e.g,. see National Assessment Synthesis Team, 2001). As Rajendra Pachauri, chair of the Intergovernmental Panel on Climate Change recently argued, "... .there is an opportunity for much political debate when you start to predict the impact of climate change on specific regions. But if you want action you must provide this information" (Schiermeier, 2003). Finally, this research demonstrates that messages about climate change need to be tailored to the needs and predispositions of particular audiences; in some cases to directly challenge fundamental misconceptions, in others to resonate with strongly held values.

\section{Appendix: Policy Preferences}

Questions (a) and (b) were adapted from a national survey conducted in 1999 by the Pew Center on Global Climate Change (1999). Question (c) was adapted from a 
national survey conducted in 1998 by the Program on International Policy Attitudes at the University of Maryland. Questions (f) through (i) were adapted from a national survey conducted in 1997 by O'Connor, Bord and Fisher (1999). Questions (d), (e) and (j) are original questions. All questions except (a) and (c) were answered using a Likert scale ranging from (1) Strongly support to (4) Strongly oppose. Most included a "Don't know" response.

(a). Do you think the United States should reduce its emissions of the greenhouse gases (carbon dioxide, methane, etc.) that are said to cause global warming? [Likert scale ranging from (1) Definitely yes to (4) Definitely no]

(b). In 1997, the United States and other developing countries made an agreement called the Kyoto Protocol to collectively reduce their emissions of greenhouse gases. The United States agreed to reduce its emissions by $7 \%$ by the year 2010 . How much do you favor or oppose this agreement?

(c). The United States currently emits about $20 \%$ of the world's total greenhouse gases. People disagree whether the U.S. should reduce greenhouse gases on its own, or make reductions only if other countries do too. Which of the following statements comes closest to your own point of view? The United States should reduce its emissions...i) regardless of what other countries do; ii) only if all other industrialized countries reduce their emissions; iii) only if all other industrialized and all less-developed countries reduce their emissions; iv) the United States should not reduce its emissions; v) don't know.

(d). One controversial proposal to solve global warming is to create an international market in greenhouse gases. In this system, all countries agree to a global cap on emissions. Each country then gets the right to emit a portion of this global amount. If a country emits more than its portion, it must buy more emission rights from other countries or else pay stiff fines. In principle, how much do you support or oppose an international market that allows countries to buy and sell greenhouse gases?

(e). Carbon dioxide is the primary greenhouse gas said to be causing global warming and is produced by electric power plants and motor vehicles (e.g., cars, trucks and sport utility vehicles). Currently, carbon dioxide is not regulated as a pollutant. How much do you support or oppose the regulation of carbon dioxide as a pollutant?

(f). The average new motor vehicle gets 29 miles per gallon of gas. Some people say we should increase average fuel efficiency to 33 miles per gallon, to help reduce carbon dioxide emissions. This would increase new motor vehicle prices by about $\$ 1,000$. How much do you support or oppose this idea? 
(g). How much do you support or oppose a 60-cent per gallon gasoline tax, over and above existing gas taxes, to encourage people to drive less and thus reduce carbon dioxide emissions?

(h). In order to encourage people to use more fuel-efficient vehicles, some people have proposed a 5 percent "gas guzzler" tax on cars, trucks and sport utility vehicles that get less than 25 miles per gallon. This would add approximately $\$ 1,000$ to the price of a $\$ 20,000$ car. How much do you support or oppose this proposal?

(i). To encourage industry to be more fuel efficient, some people have proposed a business energy tax. This tax would raise the average price of most things you buy, including food and clothing, by 3 percent, or approximately $\$ 380$ per person per year. How much do you support or oppose this proposal?

(j). The United States government provides approximately $\$ 5$ billion a year in subsidies to the fossil fuel industry (coal, oil, natural gas). Some people have proposed transferring these subsidies to the renewable energy industry (wind, solar, biomass, etc.) to develop cleaner forms of energy. This would make fossil fuels more expensive and renewable energy less expensive. How much do you support or oppose this proposal?

TABLE AI

Risk perception index

\begin{tabular}{|c|c|c|c|c|}
\hline & Mean & Std Dev & $\begin{array}{l}\text { Alpha if } \\
\text { item deleted }\end{array}$ & Alpha \\
\hline Risk Perception Index & 23.63 & 7.34 & & 0.94 \\
\hline How concerned are you about global warming? & 2.89 & 0.89 & 0.94 & \\
\hline \multicolumn{5}{|l|}{$\begin{array}{l}\text { How likely do you think it is that each of the following } \\
\text { will occur during the next } 50 \text { years due to global } \\
\text { warming? }\end{array}$} \\
\hline $\begin{array}{l}\text { Worldwide, many people's standard of living will } \\
\text { decrease. }\end{array}$ & 2.59 & 1.01 & 0.93 & \\
\hline Worldwide water shortages will occur. & 2.77 & 1.05 & 0.93 & \\
\hline Increased rates of serious disease worldwide. & 2.65 & 1.01 & 0.93 & \\
\hline My standard of living will decrease. & 2.27 & 1.05 & 0.93 & \\
\hline Water shortages will occur where I live. & 2.42 & 1.06 & 0.94 & \\
\hline My chance of getting a serious disease will increase. & 2.34 & 1.02 & 0.93 & \\
\hline $\begin{array}{l}\text { How serious of a threat do you believe global warming } \\
\text { is to non-human nature? }\end{array}$ & 3.06 & 0.93 & 0.94 & \\
\hline $\begin{array}{l}\text { How serious are the current impacts of global warming } \\
\text { around the world? }\end{array}$ & 2.64 & 0.89 & 0.94 & \\
\hline
\end{tabular}

$n=590$. Scales range from 1 (none) to 4 (very). 
TABLE AII

Egalitarian index

\begin{tabular}{|c|c|c|c|c|}
\hline & Mean & Std Dev & $\begin{array}{l}\text { Alpha if } \\
\text { item deleted }\end{array}$ & Alpha \\
\hline Egalitarianism Index & 17.84 & 4.22 & & 0.77 \\
\hline $\begin{array}{l}\text { We have gone too far in pushing equal rights } \\
\text { (reverse coded). }\end{array}$ & 2.58 & 1.04 & 0.76 & \\
\hline I support gov't. efforts to get rid of poverty. & 2.93 & 0.91 & 0.75 & \\
\hline $\begin{array}{l}\text { What this world needs is a more equal distribution } \\
\text { of wealth. }\end{array}$ & 2.40 & 0.99 & 0.71 & \\
\hline $\begin{array}{l}\text { Firms and institutions should be organized so } \\
\text { everybody can influence important decisions. }\end{array}$ & 2.59 & 0.87 & 0.75 & \\
\hline I support affirmative action. & 2.45 & 0.95 & 0.73 & \\
\hline $\begin{array}{l}\text { If people were treated more equally we would } \\
\text { have fewer problems. }\end{array}$ & 2.77 & 0.87 & 0.73 & \\
\hline $\begin{array}{l}\text { The world would be a more peaceful place if its } \\
\text { wealth were divided more equally among } \\
\text { nations. }\end{array}$ & 2.12 & 0.92 & 0.72 & \\
\hline
\end{tabular}

$n=647$. Scales range from 1 (strongly disagree) to 4 (strongly agree).

TABLE AIII

Fatalism index

\begin{tabular}{|c|c|c|c|c|}
\hline & Mean & Std Dev & $\begin{array}{l}\text { Alpha if } \\
\text { item deleted }\end{array}$ & Alpha \\
\hline National Fatalism Index & 11.47 & 3.33 & & 0.71 \\
\hline $\begin{array}{l}\text { The future is too uncertain for a person to make } \\
\text { serious plans. }\end{array}$ & 1.91 & 0.90 & 0.68 & \\
\hline $\begin{array}{l}\text { It doesn't make much difference if people elect } \\
\text { one or another political candidate, for nothing } \\
\text { will change. }\end{array}$ & 2.23 & 0.97 & 0.67 & \\
\hline I feel that life is like a lottery. & 2.02 & 0.88 & 0.66 & \\
\hline $\begin{array}{l}\text { A person is better off if he or she doesn't trust } \\
\text { anyone. }\end{array}$ & 1.74 & 0.85 & 0.67 & \\
\hline I have very little control over my life. & 1.59 & 0.76 & 0.70 & \\
\hline $\begin{array}{l}\text { It's no use worrying about public affairs; I can't } \\
\text { do anything about them anyway. }\end{array}$ & 1.98 & 0.85 & 0.62 & \\
\hline
\end{tabular}

$n=647$. Scales range from 1 (strongly disagree) to 4 (strongly agree). 
TABLE AIV

Policy preferences index

\begin{tabular}{lrlll}
\hline & & & Alpha if & \\
& Mean & Std Dev & item deleted & Alpha \\
\hline Policy Preferences Index & 19.58 & 3.68 & & 0.84 \\
Should US reduce GHG emissions? & 3.41 & 0.73 & 0.80 & \\
Support Kyoto Protocol? & 3.33 & 0.84 & 0.79 & \\
US act alone or only if other countries act? & 3.66 & 0.75 & 0.82 & \\
Support regulation of CO2 as pollutant? & 3.03 & 0.90 & 0.81 & \\
Support increase in fuel economy standards? & 3.13 & 0.90 & 0.82 & \\
Support subsidy shift to renewable energy? & 3.02 & 0.84 & 0.82 & \\
\hline
\end{tabular}

$n=609$.

Scales range from 1 (Strongly oppose) to 4 (Strongly support).

TABLE AV

Tax policy preferences index

\begin{tabular}{lllll}
\hline & & & Alpha if & \\
& Mean & Std Dev & item deleted & Alpha \\
\hline Tax policy preferences index & 6.53 & 2.56 & & 0.78 \\
Support tax on gasoline? & 1.72 & 0.95 & 0.74 & \\
Support tax on "gas guzzlers"? & 2.45 & 1.12 & 0.69 & \\
Support business energy tax? & 2.01 & 0.99 & 0.66 & \\
\hline
\end{tabular}

$n=595$.

Scales range from 1 (Strongly oppose) to 4 (Strongly support).

\section{Acknowledgments}

This material is based upon work supported by the National Science Foundation under Grant No. SES-0221896. The author would like to thank Paul Slovic, Shaul Cohen, and three anonymous reviewers for their constructive criticism and Michael Oppenheimer and Alexander Todorov for their support of this special issue.

\section{Notes}

\footnotetext{
${ }^{1}$ The terms "global climate change" and "global warming" are used interchangeably throughout this paper. While the term "global climate change" is generally preferred by the scientific community, the survey reported here used the term "global warming" as this is the term most commonly used by the media and the lay public. This and other research studies have demonstrated that the connotative meanings of "climate change" and "global warming" differ in significant ways among the lay
} 
public, but are essentially synonymous among particular groups (e.g., climate change activists). See Leiserowitz (2003).

${ }^{2}$ These associations tap the most readily available features of an individual's full mental model. These "top-of-the-head" associations are often the most salient and influential components of a full mental model, especially for experientially-based judgments and decisions. Individuals typically access and utilize their full mental model only when engaging in deeper analysis and deliberation about an issue. Methodologically, associations are relatively easy to collect in representative surveys, while full mental models can be reconstructed only using in-depth and typically non-representative methods. Ultimately, the two methods are complimentary and indeed have found convergent evidence for pervasive misunderstandings, such as the lay public's common conflation of ozone depletion with climate change.

${ }^{3}$ Based on the $92 \%$ of Americans who had heard of global warming.

${ }^{4}$ Holistic, unipolar, positive affect was not a significant predictor in any of the affect models of risk perception or policy preferences and was therefore not included.

${ }^{5}$ It is possible that more than $17 \%$ of Americans would support a gasoline tax of less than the 60 cents per gallon proposed in this 2002 survey. For example, in the midst of the Kyoto Protocol negotiations in November, 1997, a Mellman Group poll found that $48 \%$ of Americans said they would support a 10 cent per gallon gasoline tax if the money was "earmark[ed] for research and development of alternative fuels and technologies" "to reduce the threat of global warming" (PIPA, 2005). On the other hand, a national survey conducted in May 2005 found that only 15\% of Americans thought it a good idea to "increase the tax per gallon of gasoline" as a way "of reducing U.S. dependence on imported oil" - a significantly more salient concern for Americans than climate change as also found in this survey (Yale University, 2005). These divergent results are probably conditioned by the gas prices extant and the salience of climate change and other related issues at the time of survey implementation, as well as the specific wording of the questions, especially the use of the word "tax." Nonetheless, all of these limited data suggest that Americans are generally predisposed against higher gasoline taxes.

\section{References}

Alhakami, A. S. and Slovic, P.: 1994, 'A psychological study of the inverse relationship between perceived risk and perceived benefit', Risk Anal. 14, 1085-1096.

Benthin, A., Slovic, P., Moran, P., Severson, H., Mertz, C. K., and Gerrard, M.: 1995, 'Adolescent health-threatening and health-enhancing behaviors: A study of word association and imagery', $J$. Adoles. Health. 17, 143.

Bostrom, A., Morgan, M. G., Fischhoff, B., and Read, D.: 1994, 'What do people know about global climate change?' Risk Anal. 14, 959-970.

Dake, K.: 1991, 'Orienting dispositions in the perception of risk: An analysis of contemporary worldviews and cultural biases', J. Cross-Cult. Psychol. 22, 61-82.

Dake, K.: 1992, 'Myths of nature: Culture and the social construction of risk', J. Soc. Iss. 48, 21-27.

Dake, K. and Wildavsky, A.: 1990, 'Theories of risk perception: Who fears what and why?' Daedalus. 119, 41-60.

Dake, K. and Wildavsky, A.: 1991, 'Individual Differences in Risk Perception and Risk-Taking Preferences', in Garrick, B. J. and Geckler, W. C. (eds.), The Analysis, Communication, and Perception of Risk, Plenum, New York, pp. 15-24.

Damasio, A. R.: 1994, Descartes' Error: Emotion, Reason, and the Human Brain, Grosset/Putnam, New York.

Damasio, A.: 1999, The Feeling of What Happens. Harcourt, Inc., New York.

Dillman, D. A.: 2000, Mail and Internet Surveys: The Tailored Design Method. 2nd ed. J. Wiley, New York. 
Douglas, M.: 1966, Purity and Danger: An Analysis of Concepts of Pollution and Taboo. Routledge and Kegan Paul, London.

Douglas, M.: 1970, Natural Symbols: Explorations in Cosmology. Barrie and Rockliff, London.

Douglas, M., Gasper, D., Ney, S., and Thompson M.: 1998, 'Human Needs and Wants', in Rayner, S. and Malone, E. L. (eds.), Human Choice and Climate Change, Battelle Press, Columbus, pp. 195-264.

Douglas, M. and Wildavsky, A.: 1982, Risk and Culture: An Essay on the Selection of Technological and Environmental Dangers. University of California Press, Berkeley.

Dunlap, R. E. and Saad, L.: cited 2001, 'Only One in Four Americans Are Anxious About the Environment', [Available online from http://www.gallup.com/poll/content/login.aspx?ci=1801.]

Eagley, A. H. and Chaiken, S.: 1998, 'Attitude Structure and Function', in Gilbert, D. T., Fiske, S. T., and Lindzey, G. (eds.), The Handbook of Social Psychology, 4th ed. McGraw-Hill, New York, pp. 269-322.

Epstein, S.: 1994, 'Integration of the cognitive and the psychodynamic unconscious', Am. Psychol. 49, 709-724.

Finucane, M. L., Alhakami, A. Slovic, P. and Johnson, S. M.: 2000, 'The affect heuristic in judgments of risks and benefits', J. Beh. Dec. Mak. 13, 1-17.

Jaeger, C. C., Renn, O., Rosa, E. A., and Webler, T.: 1998, 'Decision Analysis and Rational Action', in Rayner, S. and Malone, E. L. (eds.), Human Choice and Climate Change, Battelle Press, Columbus, pp. 141-216.

Jenkins-Smith, H.: 2001, 'Modeling Stigma: An Empirical Analysis of Nuclear Images of Nevada', in Flynn, J., Slovic, P., and Kunreuther, H. (eds.), Risk, Media and Stigma, Earthscan, London, pp. 107-131.

Kempton, W., Boster, J. S., and Hartley, J. A.: 1995, Environmental Values in American Culture. MIT Press, Cambridge.

Leiserowitz, A.: 2005, 'American risk perceptions: Is climate change dangerous?', Risk Anal. 25, 1433-1442.

Leiserowitz, A.: 2003, Global Warming in the American Mind: The Roles of Affect, Imagery, and Worldviews in Risk Perception, Policy Preferences and Behavior, Environmental Science, Studies and Policy, University of Oregon.

Loewenstein, G.: 1996, 'Out of control: Visceral influences on behavior', Org. Beh. Hum. Dec. Process. 65, 272-292.

Loewenstein, G., Weber, E., Hsee, C., and Welch, E.: 2001, 'Risk as feelings', Psychol. Bull. 127, 267-286.

Maio, G. R., Olson, J. M., Bernard, M. M., and Luke, M. A.: 2003, 'Ideologies, Values, Attitudes, and Behavior', in Delamater, J. (ed.), Handbook of Social Psychology, Kluwer Academic/Plenum Publishers, New York, pp. 283-308.

Marland, G., Boden, T., and Andres, B.: cited 2003, 'Trends: A Compendium of Data on Global Change', [Available online from http://cdiac.esd.ornl.gov/trends/emis/top2000.tot.]

Milton, K.: 1996, Environmentalism and Cultural Theory: Exploring the Role of Anthropology in Environmental Discourse. Routledge, New York.

National Assessment Synthesis Team (U.S.): 2001, Climate Change Impacts on the United States: The Potential Consequences of Climate Variability and Change: Foundation. Cambridge University Press, New York.

Nisbett, R. E. and Ross, L.: 1980, Human Inference: Strategies and Shortcomings of Social Judgment. Prentice-Hall, Englewood Cliffs, NJ.

O'Connor, R. E., Bord, R. J., and Fisher, A.: 1999, 'Risk perceptions, general environmental beliefs, and willingness to address climate change', Risk Anal. 19, 461-471.

O'Riordan, T. and Jordan, A.: 1999, 'Institutions, climate change and cultural theory: Towards a common analytical framework', Glob. Env. Change. 9, 81-93. 
Osgood, C., Suci, G. J., and Tannenbaum, P. H.: 1957, The Measurement of Meaning. University of Illinois Press, Chicago.

Pendergraft, C. A.: 1998, 'Human dimensions of climate change: Cultural theory and collective action', Clim. Change. 39, 643-666.

Peters, E. and Slovic, P.: 1996, 'The role of affect and worldviews as orienting dispositions in the perception and acceptance of nuclear power', J. Appl. Soc. Psychol. 26, 1427.

Petty, R. E., Wedener, D. T., and Fabrigar, L. R.: 1997, 'Attitudes and attitude change', Ann. Rev. Psychol. 48, 609-647.

Pianin, E. and Goldstein, A.: 14 March 2001, 'Bush Drops a Call for Emission Cuts', The Washington Post, p. A01.

PIPA: cited 2005, 'Data: Global Warming - Readiness to Accept Increases in Energy Costs', [Available online from http://65.109.144.44/digest/global_issues/global_warming/questionnaire5.cfm.]

Read, D., Bostrom, A., Morgan, M. G., Fischhoff, B., and Smuts, T.: 1994, 'What do people know about global climate change? Survey results of educated laypeople', Risk Anal. 14, 971982.

Revkin, A.: 17 March 2001, 'Bush's Shift Could Doom Air Pact, Some Say', The New York Times, p. 7.

Rippl, S.: 2002, 'Cultural theory and risk perception: A proposal for a better measurement', J. Risk Res. 5, 147-165.

Satterfield, T.: 2001, 'Risk Lived, Stigma Experienced: Reflections on the Limits of Adaptations', in Flynn, J., Slovic, P., and Kunreuther, H. (eds.), Risk, Media and Stigma, Earthscan, London, pp. 69-86.

Schiermeier, Q.: 2003, 'Climate panel to seize political hot potatoes', Nature 421, 879.

Schiermeier, Q.: 1997, Senate Resolution 98. 105 ed.

Slovic, P.: 1997, 'Trust, Emotion, Sex, Politics and Science: Surveying the Risk-Assessment Battlefield', in Bazerman, M., Tenbrunsel, A., and Wade-Benzoni, K. (eds.), Environment, Ethics and Behavior, New Lexington Press, San Francisco, pp. 277-313.

Slovic, P.: 2000, The Perception of Risk. Earthscan, London.

Slovic, P., Finucane, M. L., Peters, E., and MacGregor, D. G.: 2002, 'The Affect Heuristic', in Gilovich, T., Griffin, D., and Kahneman, D. (eds.), Heuristics and Biases: The Psychology of Intuitive Judgment, Cambridge University Press, New York, pp. 397-420.

Slovic, P., Layman, M., and Flynn, J. H.: 1991, 'Perceived risk, trust, and the politics of nuclear waste', Science, 254, 1603-1608.

Slovic, P., MacGregor, D. G., and Peters, E.: 1998, 'Imagery, Affect, and Decision-Making', Decision Research, Eugene, OR.

Slovic, P. and Peters, E.: 1998, 'The importance of worldviews in risk perception', Risk Decision and Policy 3, 165-170.

Steg, L. and Sievers, I.: 2000, 'Cultural theory and individual perceptions of environmental risks', Env. Beh. 32, 250-269.

Szalay, L. B. and Deese, J.: 1978, Subjective Meaning and Culture: An Assessment Through Word Associations, Lawrence Erlbaum Associates, Hillsdale, NJ.

U.S. Census Bureau, Population Division: cited 2005, 'U.S. and World Population Clocks', [Available online from http://www.census.gov/main/www/popclock.html.]

United States National Energy Policy Development Group and United States President (2001- : Bush): 2001, Reliable, Affordable, and Environmentally Sound Energy for America's Future: Report of the National Energy Policy Development Group, U.S. Government Printing Office, Washington, DC.

Yale University: cited 2005, 'Survey on American Attitudes on the Environment - Key Findings', [Available online from http://www.yale.edu/envirocenter/yaleenvironmentpollspring 2005releasetopline.pdf.] 
Yankelovich, D.: 1991, 'Coming to Public Judgment: Making Democracy Work in a Complex World. 1 st ed. The Frank W. Abrams Lectures, Syracuse University Press, Syracuse, New York.

Yankelovich, D.: cited 2002, 'The Seven Stages of Public Opinion', [Available online from http://www.publicagenda.org/aboutpubopinion/aboutpubop7.htm.]

Zajonc, R. B.: 1980, 'Feeling and thinking: preferences need no inferences', Am. Psychol. 35, 151175.

(Received 21 April 2005; in revised form 28 November 2005) 